\title{
Identification of anti-inflammatory compound/compounds in hexane fraction of Jatropha curcas root extract
}

\author{
Ahmad Razi Othman ${ }^{\mathrm{a}, \mathrm{ef}}$, Intan Safinar Ismail ${ }^{\mathrm{a}, \mathrm{b}^{*}}$, Norhani Abdullah ${ }^{\mathrm{c}}$, Syahida Ahmad ${ }^{\mathrm{d}}$ \\ ${ }^{a}$ Laboratory of Natural Product, Institute Bioscience, Universiti Putra Malaysia, 43400 Serdang, Selangor Darul Ehsan, Malaysia \\ ${ }^{b}$ Department of Chemistry, Faculty of Science, Universiti Putra Malaysia 43400 UPM Serdang Selangor Darul Ehsan, Malaysia \\ 'Institute of Tropical Agriculture and Food Security, Universiti Putra Malaysia 43400 UPM Serdang Selangor Darul Ehsan, Malaysia \\ ${ }^{d}$ Department of Biochemistry, Faculty of Biotechnology and Biomolecular Sciences, Universiti Putra Malaysia, 43400 Serdang, Selangor Darul \\ Ehsan, Malaysia \\ ${ }^{\circ}$ Chemical Engineering Programme, Faculty of Engineering and Built Environment, Universiti Kebangsaan Malaysia, 43600 UKM Bangi, \\ Selangor Darul Ehsan, Malaysia \\ ${ }^{f}$ Research Centre for Sustainable Process Technology, Faculty of Engineering and Built Environment, Universiti Kebangsaan Malaysia, 43600 \\ UKM Bangi, Selangor Darul Ehsan, Malaysia
}

Received 12th February 2019 / Accepted 19th August 2019

\begin{abstract}
Jatropha curcas is a medicinal plant with many therapeutic properties such as anti-inflammatory, anti-malaria, anti-cancer and antioxidant. The root extract has been shown to possess high antiinflammatory activity. Previously, the compounds responsible for this activity have not been fully elucidated. Two fractions (Fraction 1 and Fraction 2) obtained from a preparative HPLC of the root extract showed significant anti-inflammatory and cytotoxic activities in RAW 264.7 murine macrophage cells with Fraction 1 giving higher nitric oxide (NO) inhibition compared to Fraction 2 and L-NAME. Further purification steps involving column chromatography, thin layer chromatography and analytical HPLC of Fraction 1 produced two fractions labeled as Fraction A and Fraction B. Both fractions showed anti-inflammatory activity without cytotoxic activity in RAW 264.7 cells. Liquid chromatography tandem mass spectrometry (LC-MS/MS) analysis showed that Fraction A contained a group of 18 carbon fatty acid compounds consisting of 2 oxooctadecanoic acids; 15, 16 dihydroxy 9Z, $12 \mathrm{Z}$ octadecadienoic acid; octadecadienoic isomer and 15,16 dihydroxy 9Z, 12Z octadecadienoic acid, 15S, 16S. The 18-carbon fatty acid structure was confirmed by nuclear magnetic resonance (NMR) spectral data. The $\mathrm{IC}_{50}$ value of compounds in Fraction A for anti-inflammatory activity in RAW 264.7 cell line was $434.8 \pm 0.75 \mu \mathrm{g} / \mathrm{mL}$. From the analysis, it can be concluded that Fraction A can be classified under 18 carbon long chain fatty acid group based on LC MS/MS and NMR analysis. This active compound shows an inhibition towards NO activity.
\end{abstract}

Keywords: Jatropha curcas, anti-inflammatory, C 18 fatty acids, octadecanoic acid, $\mathrm{IC}_{50}$

\section{INTRODUCTION}

Jatropha curcas Linn. belongs to the Euphorbiaceae family with about 170 known species (Sabandar et al., 2013). The word Jatropha was derived from two
Greek words of "jatrós" means "doctor" and "trophe" means "food" (Kumar and Sharma, 2008). Although it was a native plant of Mexico

*Author for correspondence: Intan Safinar Ismail, Laboratory of Natural Product, Institute Bioscience, Universiti Putra Malaysia, 43400 Serdang, Selangor Darul Ehsan, Malaysia; Department of Chemistry, Faculty of Science, Universiti Putra Malaysia 43400 UPM Serdang Selangor Darul Ehsan, Malaysia. Email - safinar@upm.edu.my 
and Central America, the plant is now widespread in other parts of the world including South-east Asia, India and Africa. It has gained importance in Malaysia as a source of seed oil for biofuel production. In many African and Asian countries, J. curcas plant is considered a traditional herb to cure various ailments ranging from simple fever to infectious diseases, including sexually transmitted (Pandey et al., 2012). In the tropics and Central America, Jatropha seeds are used as a purgative and supplement in tea drinks. However, this practice was believed to cause strong irritation, poisoning and cancer (Adolf et al., 1984). A research conducted in Sri Lanka showed that Jatropha seeds could also be used as a pregnancy abortifacient (Goonasekera et al., 1995). However, in Mexico, the seeds are roasted or boiled before being used as an ingredient in traditional cuisines (Makkar et al., 1998).

The Jatropha leaves have been used to treat various illnesses. The Mayan used leaves parts to treat rashes and bone fracture (Comerford, 1996). In Ghana, the leaves were used for anti-malarial treatment by boiling the leaves and using the extract as a drink (Asase et al., 2005). The plant leaves had also been reported to be low in sodium and considered appropriate for a person who practiced low sodium diet (Méndez et al., 2014). The latex from Jatropha tree also possesses medicinal property, whereby in Indonesia, the latex was used to treat infected wounds and ulcer (van den Berg et al., 1995). The Jatropha root is also useful in the treatment of certain diseases. A report from Brazil claimed that the extract from Jatropha rhizome could treat Schistosomiasis mansonica disease that is caused by $S$. mansoni worm present in a fresh-water mollusk Biomphalaria glabrata which infects the liver (dos Santos and Sant'Ana, 1999). Another property of Jatropha root extract is the anti-inflammatory activity on RAW 264.7 macrophage cells (Mujumdar and Misar, 2004; Nayak and Patel, 2010). Our previous report (Othman et al., 2015) showed that the anti-inflammatory activity of J.curcas root was due to the presence of fatty acids. However, the nature of the active fatty acids was unknown. Thus, the present study was conducted to elucidate the structure of the active fatty acids involved in the anti-inflammatory activity.

\section{MATERIALS AND METHODS}

\section{Purification of compounds by chromatographic methods}

Jatropha curcas L. roots were obtained from Farm 2, Faculty of Agriculture, Universiti Putra Malaysia (UPM). The plant was verified by the botanist, Dr. Shamsul Khamis at the Institute of Bioscience, UPM and deposited in the Phytomedicinal Herbarium, Institute of Bioscience, UPM with voucher number SK1764/2010. The root sample was extracted with $80 \%$ methanol, followed by liquid partition chromatography (Othman et al., 2015). The hexane fraction which showed high antiinflammatory activity was subjected to preparative high-performance liquid chromatography (HPLC). Two fractions (Fraction 1 and Fraction 2) obtained showed significant anti-inflammatory and cytotoxic activities in RAW 264.7 murine macrophage cells. The fractions were further purified by a mini open column $(1 \times 4 \mathrm{~cm})$, packed with silica gel 60:70-230 Mesh (ASTM) and prewashed with hexane: ethyl acetate (EtOAc) (7:3). A sample of $1 \mathrm{~mL}(20.0 \mathrm{mg} / \mathrm{mL})$ was loaded and eluted with $3 \mathrm{~mL}$ of hexane:EtOAc (7:3). The mobile phase, consisted of $20 \mathrm{~mL}$ hexane:EtOAC solution (6:4) was used to collect $1 \mathrm{~mL}$ eluates. The eluates were subjected to analytical thin layer chromatography (TLC) on silica gel $60 \mathrm{~F}_{245}(0.25$ $\mathrm{mm}$ thickness) coated plates and developed in hexane:EtOAc (6:4). The spots were viewed under UV at the wavelength of $254 \mathrm{~nm}$ (short wave) and $360 \mathrm{~nm}$ (long wave). The spots with similar profiles were pooled and air dried. The dried samples were first dissolved in hexane and were analyzed by analytical HPLC. A JASCO Liquid Chromatography System consisting of a JASCO Pump PU-2089 Plus and JASCO Absorbance Detector model UV-2077 Plus 4Intelligent UV/VIS Detector linked by JASCO BORWIN version 1.5 software was used. The analysis was conducted by using an Agilent column, ZORBAX Eclipse XDB-C18 (4.6 x 250 $\mathrm{mm}: 5 \mu \mathrm{m})$. The solvent system was $\mathrm{MeOH}: \mathrm{H}_{2} \mathrm{O}$ in a ratio that ranged from $2 \%$ to $100 \%$ of $\mathrm{H}_{2} \mathrm{O}$ in a gradient mode at a flow rate of $1.0 \mathrm{ml} / \mathrm{min}$. The gradient was set at $2 \%$ of $\mathrm{H}_{2} \mathrm{O}$ from 0 to 5 minutes, continuously increasing the water percentage to $5 \%$ from $5 \mathrm{~min}$ to $20 \mathrm{~min}$. After 20 
minutes, the water percentage was increased to $20 \%$ for $10 \mathrm{~min}$ before $100 \% \mathrm{MeOH}$ was used to flush the column for $30 \mathrm{~min}$. Two fractions (Fraction A and Fraction B) obtained from this analysis were subjected to anti-inflammatory and cytotoxic assays.

\section{Compound analyses}

Fraction A which showed higher antiinflammatory activity without cytotoxic activity than Fraction B was used for identification of compounds present in the fraction. The fraction was analyzed by Liquid Chromatography Tandem Mass Spectrometry (LCMS/MS) and Nuclear Magnetic Resonance (NMR). LCMS/MS analysis was done using AB Sciex 3200QTrap LCMS with Perkin Elmer FX 15 UHPLC system. An Agilent Zorbax C18 (150 mm x $4.6 \mathrm{~mm}$ : 5um) was used as the column. The mobile phase consisted of $\mathrm{A}$ (water) and B (acetonitrile). Both solvents A and $B$ contained $0.1 \%$ formic acid and $5 \mathrm{mM}$ ammonium formate. A gradient was programmed at $10 \% \mathrm{~B}$ to $90 \% \mathrm{~B}$ from 0.01 to $8.0 \mathrm{~min}$, hold for 2 min and back to $10 \% \mathrm{~B}$ in $0.1 \mathrm{~min}$ with reequilibration for $5 \mathrm{~min}$. The sample volume was set at $20 \mu \mathrm{L}$ per injection.

Proton-1 and carbon-13 NMR analyses were carried out on Varian NMR system $500 \mathrm{MHz}$ at 500 and $125 \mathrm{MHz}$ respectively. The signals obtained were described in terms of chemical shifts $(\delta \mathrm{ppm})$, multiplicity, coupling constants and a number of protons and carbons where appropriate. Both $1 \mathrm{D}$ and $2 \mathrm{D} \mathrm{NMR}$ were measured in deuterated chloroform $\left(\mathrm{CDCl}_{3}\right)$.

\section{Anti-inflammatory, cytotoxic assay and $I C_{50}$ value determination}

Murine monocytic macrophage RAW 264.7 cell were cultured in Dulbecco's Modified Eagle Media (DMEM) with $4 \mathrm{mM} \mathrm{L-glutamine,} 45 \mathrm{~g} / \mathrm{L}$ glucose, $1 \mathrm{mM}$ sodium pyruvate and $10 \%$ of fetal bovine serum (FBS). The cells were incubated in a $50 \mathrm{ml}$ culture flask in a $\mathrm{CO}_{2}$ incubator with $5 \%$ of $\mathrm{CO}_{2}$ at $37^{\circ} \mathrm{C}$. Then the RAW 264.7 cells were seeded in a 96-well microplate $\left(1 \times 10^{6} \mathrm{cell} / \mathrm{mL}\right)$ and incubated in $5 \% \mathrm{CO}_{2}$ at $37^{\circ} \mathrm{C}$ for 2 to 3 hours. Different volumes with final concentration (1.0, $0.5,0.25,0.125 \mathrm{mg} / \mathrm{mL}$ ) of sample were diluted in DMSO were added to the wells by serial dilution for $\mathrm{IC}_{50}$ determination. The cells were then stimulated by adding $100 \mathrm{U} / \mathrm{mL}$ of IFN- $\gamma$ and 5 $\mathrm{ug} / \mathrm{mL}$ of LPS from Escherichia coli strain 055:B5. The cells were incubated in $5 \% \mathrm{CO}_{2}$ at $37^{\circ} \mathrm{C}$ for 18 hours. The nitric oxide (NO) concentration produced by RAW 264.7 cell was determined by Griess assay (Syahida et al., 2006). N-nitro-larginine-methyl ester (L-NAME) which acted as iNOS inhibitor was used as a positive control at a concentration of $250 \mu \mathrm{M}$. The cytotoxic effect of the sample was determined by using 3-(4,5dimethylthiazol-2-yl)-2,5-diphenyltetrazolium bromide (MTT) assay (Syahida et al., 2006). All experiments were done in triplicate.

\section{Statistical analysis}

All data were subjected to one-way analysis of variance (ANOVA). Treatment means were compared using Tukey's multiple comparison tests. The $\mathrm{IC}_{50}$ value was determined by using onephase decay analysis. Statistic software Graphpad Prism 5.0 (Graphpad Software Inc., San Diego, CA) was used for all statistical analyses.

\section{RESULTS AND DISCUSSION}

\section{Anti-inflammatory activity of Fraction $A$ and Fraction B}

The analytical HPLC analysis produced two fractions labeled as Fraction A and Fraction B. Fraction A showed a higher nitric oxide (NO) inhibition than Fraction B and L-NAME as shown in Figure 1a. Both fractions were non-toxic towards RAW 264.7 cells growth (Figure 1b). The purification steps conducted with the methanolic extract of $J$. curcas produced an active antiinflammatory fraction without cyctotoxicity activity. The non-toxic property is an important consideration as the anti-inflammatory assay was based on the measurement of $\mathrm{NO}$ production and a decreased in $\mathrm{NO}$ quantity could also mean cell death. As shown by the MTT assay from previous analysis, the hexane fraction caused cell death, while the Griess assay showed a reduction in NO production (as an indication of anti-inflammatory activity) of the RAW 264.7 macrophage cells (Othman et al., 2015). After a series of purification steps, the fractions obtained (Fraction A and B), showed an anti-inflammatory activity and were non-toxic towards RAW 264.7 macrophage cells. This indicates that the compounds extracted were 
actually inhibiting the NO production of the RAW 264.7 macrophage cells through inhibition of NO signaling pathway.

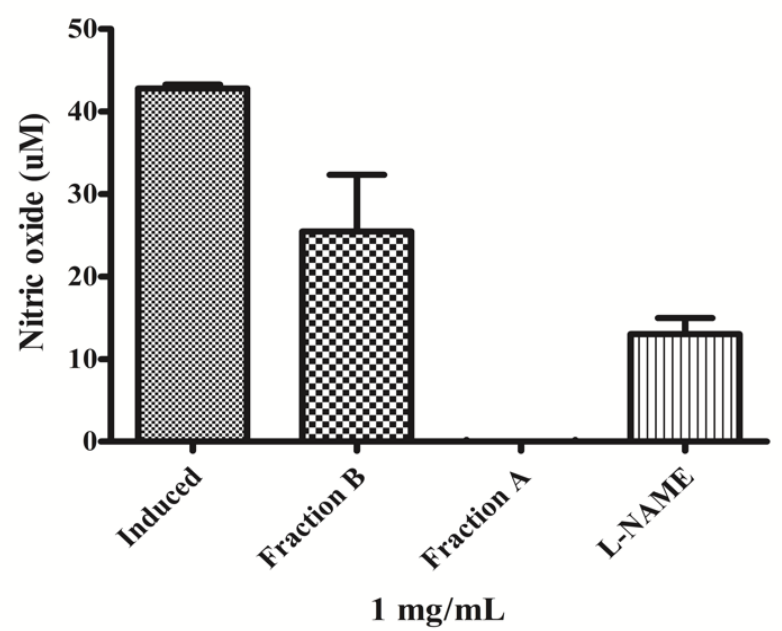

Figure 1a. Anti-inflammatory activity of Fraction $A$ and Fraction B. Fraction A exhibited a higher anti-inflammatory activity compared to Fraction $B$ and L-NAME. L-NAME and induced cells represented the positive and negative control, respectively. Each histogram represents a mean of three replicates with error bar representing the standard deviation. *Indicates significant difference $(\mathrm{P}<0.05)$ compared to the experiment control.

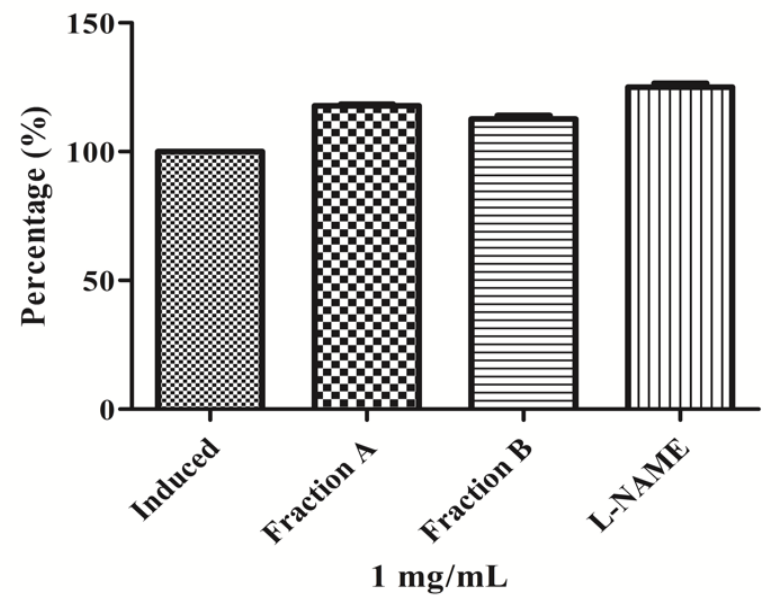

Figure 1b. Cytotoxic activity of Fraction $A$ and Fraction B. Both fractions showed no cytotoxic activity towards RAW 264.7 murine macrophage cells growth. Each histogram represents a mean of three replicates with error bar representing the standard deviation. *Indicates significant difference $(\mathrm{P}<0.05)$ compared to the experiment control

\section{Elucidation of active compound by LCMS/MS and NMR}

Analysis by LCMS/MS negative mode showed four major peaks in Fraction A that belonged to long chain fatty acid group (Figure 2). The data were then compared with the databases of ACD/Labs advanced chemometrics mass fragmentations predictive software. According to the database analysis, the four compounds with almost similar $\mathrm{m} / \mathrm{z}$ values belonged to the octadecadienoic acid and an octadecanoic acid group (Figure 2). The compounds nomenclature and their mass values are shown in Table 1 . The compounds identified were 12 oxooctadecanoic acid (Figure 2a), a substituted saturated C18 fatty acid; 15, 16 dihydroxy 9Z, 12Z octadecadienoic acid (Figure 2b), a substituted unsaturated C18 fatty acid; octadecadienoic isomer (Figure 2c), an unsaturated $\mathrm{C} 18$ fatty acid and octadecanoic acid isomer (Figure 2d), a saturated C18 fatty acid.

The chemical structures of compounds in Fraction A were confirmed by NMR analysis. The NMR data which were analyzed by using ACD/NMR software from ACD/Labs.com are presented in Table 2. The peak signals were assigned at $\delta_{\mathrm{H}} 0.88(\mathrm{t}, J=6.6 \mathrm{~Hz}, 2 \mathrm{H}), 1.26$ (br.s., $28 \mathrm{H}), 1.63(\mathrm{~m}, 2 \mathrm{H})$, and $2.34(\mathrm{t}, J=7.5 \mathrm{~Hz}, 2 \mathrm{H})$. Proton-1 and carbon-13 peak analysis are presented in Figure $3 \mathrm{a}$ and $3 \mathrm{~b}$, respectively. Although, a fifth peak was observed in the LCMS/MS spectrum, but the structure was not verified by NMR spectral data. Hence, the compound was unidentified.

The LCMS/MS analysis showed the presence of four compounds as members of the $\mathrm{C} 18$ fatty acids. The correlations of $\mathrm{C}-\mathrm{H}$ according to the NMR data were in agreement with the structure belonging to a long chain fatty acid due to the presence of carboxylic group peak at $180 \mathrm{ppm}$. No aromatic group was observed in the C13 analysis. Hence, the results of both LCMS/MS and NMR analyses were in agreement that the compounds present in the active Fraction A were C18 fatty acids.

However, the results obtained in the present study could not identify the specific compound responsible for the anti-inflammatory without cytotoxic activity. It is possible that all the fatty acids identified possessed anti-inflammatory activity as previous reports have shown that long chain fatty acids such as linolenic acid, linoleic 
acid, palmitoleic acid and octadecadienoic acid possessed anti-inflammatory activity (Ballou and Cheung, 1985; Mathavi and Velavan, 2013), these fatty acids was proven to regulate the antiinflammatory pathway (Aparna et al., 2012). The anti-inflammatory mechanism of fatty acid was shown by using enzyme kinetic study and X-ray crystallography analysis (Kudo and Murakami, 2002). It was reported that the carboxylic group from saturated fatty acid binds to the amino acid Asn 67 of the hydrophobic region of the phospholipase $\mathrm{A}_{2}\left(\mathrm{PLA}_{2}\right)$ active site (Kudo and Murakami, 2002). Based on the fatty acid mechanism explained earlier, it can be assumed that fatty acids competed with $\mathrm{PLA}_{2}$ substrate, thus acting as a competitive inhibitor towards $\mathrm{PLA}_{2}$. This enzyme is involved in catalyzing the release of arachidonic acid, a precursor for the synthesis of inflammatory mediators at the $s n-2$ position of membrane phospholipid (Diaz and Arm, 2003; Calder, 2004).

Table 1. Compounds identified by LC-MS/MS in Fraction A.

\begin{tabular}{|c|c|}
\hline Compund name & $\mathrm{m} / \mathrm{z}$ \\
\hline 12 Oxooctadecanoic acid (Figure 2a) & 183.1 \\
\hline $\begin{array}{l}\text { 15,16-Dihydroxy-9Z,12Z- } \\
\text { octadecadienoic acid (Figure 2b) }\end{array}$ & 183.0 \\
\hline Octadecadienoic acid isomer (Figure 2c) & 184.0 \\
\hline Octadecanoic acid isomer (Figure 2d) & 183.0 \\
\hline
\end{tabular}

Table 2. 2D-NMR spectral data of Fraction A.

\begin{tabular}{cccc}
\hline $\boldsymbol{\delta}_{\mathrm{H}}$ (in ppm) & $\boldsymbol{\delta}_{\mathrm{C}}$ (in ppm) & COSY (in ppm) & HMBC (in ppm) \\
\hline $0.88,2 \mathrm{H}, t, J=6.6$ & 14.1 & $1.63(\mathrm{~s}), 1.26$ & $22.6,31.9$ \\
$1.26,28 \mathrm{H}$, br.s (Overlapped) & $22.7,24.7,29.7,31.9$ & 1.63 & $14.1,22.6,31.9$ \\
$1.63,2 \mathrm{H}, m, J=7.5$ & 24.7 & 2.34 & $180,34.1$ \\
$2.34,2 \mathrm{H}, t, J=7.5$ & 34.1 & $1.26,1.63$ & $180,29.7,24.7$ \\
\hline
\end{tabular}
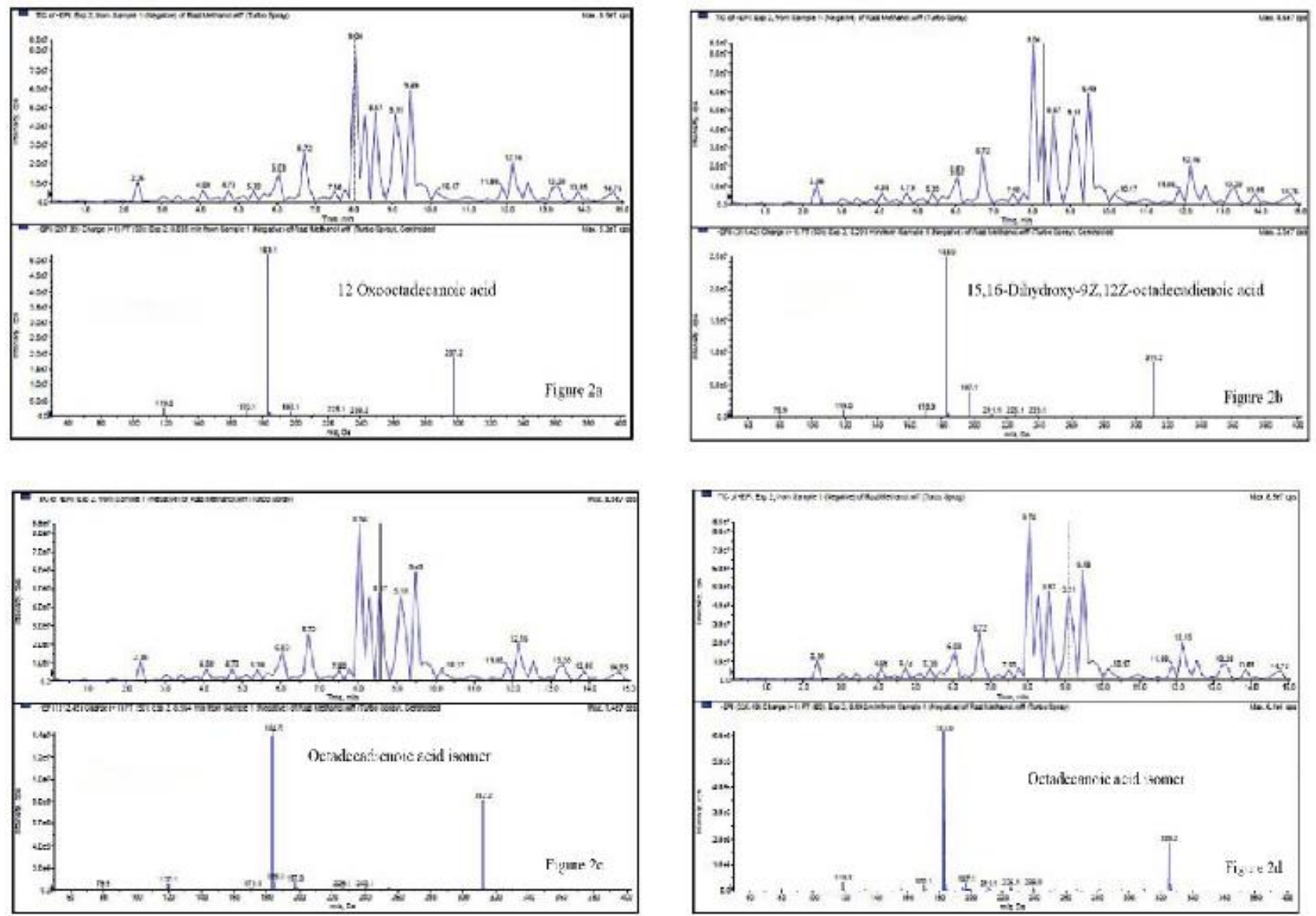

Figure 2. LC-MS/MS spectrum. Compounds 1 to 4 of Fraction A were assigned based on comparison to databases. 

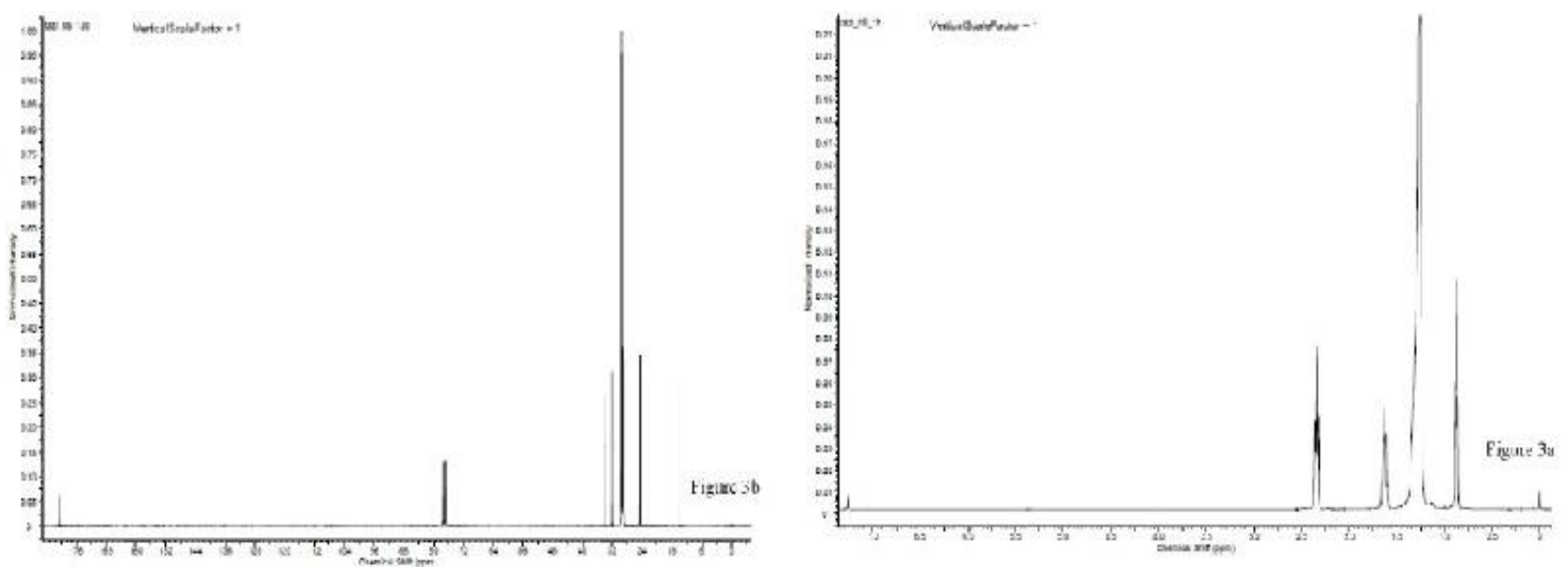

Figure 3. NMR spectrum of Fraction A (a) ${ }^{1} \mathrm{H}-\mathrm{NMR}$ spectrum $\left(\mathrm{CDCl}_{3} ; 500 \mathrm{MHz}\right)$ and (b) ${ }^{13} \mathrm{C}-\mathrm{NMR}$ spectrum $\left(\mathrm{CDCl}_{3} ; 125 \mathrm{MHz}\right)$.

\section{Inhibitory concentration of active compounds in Fraction $A$}

Inhibitory concentration $\left(\mathrm{IC}_{50}\right)$ indicates the amount of sample concentration that could inhibit $50 \%$ of $\mathrm{NO}$ production in RAW 264.7 macrophage cells. A series of sample concentrations ranging from 0.0 to $1.0 \mathrm{mg} / \mathrm{mL}$ were evaluated. Sample absorbance was measured at $550 \mathrm{~nm}$ and $\mathrm{IC}_{50}$ graph was plotted using Graphpad Prism 5 software. The $\mathrm{IC}_{50}$ value of the active compounds in Fraction A was determined to be $434.8 \pm 0.75 \mu \mathrm{g} / \mathrm{mL}$ (Figure 4).

Inhibitory concentration assay of Fraction $\mathrm{A}$ showed an $\mathrm{IC}_{50}$ value of $434.8 \pm 0.75 \mu \mathrm{g} / \mathrm{mL}$ in murine macrophage RAW 264.7 cells. In an earlier study, Oskoueian et al. (2011) reported a concentration of $3.1 \mu \mathrm{g} / \mathrm{mL}$ of methanolic extract of $J$. curcas root could inhibit $\mathrm{NO}$ production almost completely in RAW 264.7 macrophage cells (Oskoueian et al., 2011). However, the latter authors also observed that the crude extract was toxic to the cells. This raised the question whether NO inhibition was actually the result of cell death or the anti-inflammatory activity per se. On the other hand, it was clearly shown in the present study that the isolated compounds in Fraction A from the J. curcas root were non-toxic to the RAW 264.7 macrophage cells. Even though the $\mathrm{IC}_{50}$ value for the present study was higher compared to the previous report, it proved that the inhibition of compounds in Fraction A was due to the inhibition of NO signaling pathway and not by the toxicity effect towards RAW 264.7 growth.

The presence of active compounds which showed NO inhibition from other plant sources has been reported. A crude extract from Porphyra dentata (seaweed) showed more than 95\% inhibition of NO production at $200 \mu \mathrm{g} / \mathrm{mL}$ with more than $90 \%$ of cell viability (Kazłowska et al., 2010), while extract of Phaleria macrocarpa, (a tropical herbal plant), showed the highest inhibition of NO production in RAW 264.7 cells at $3.13 \mu \mathrm{g} / \mathrm{mL}$ (Hendra et al., 2011). A hexane fraction prepared from Orostachys japonicas at 100 $\mu \mathrm{g} / \mathrm{mL}$ showed inhibition of NO production in RAW 264.7 cells with cell viability over 80\% (Lee et al., 2013). These inhibitory concentrations were lower than the value observed in the present study. This is not surprising as crude extract might contain a complex mixture of compounds that would possibly work synergistically to give a potent anti-inflammatory activity compared to a single compound.

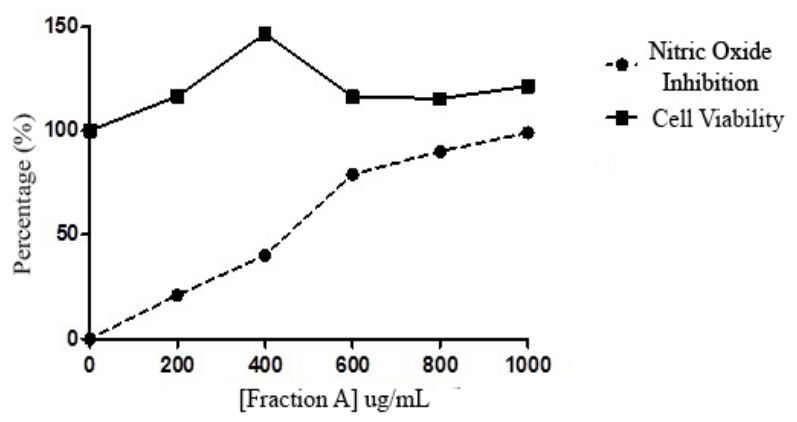

Figure 4. An $\mathrm{IC}_{50}$ analysis of anti-inflammatory activity of Fraction A. The $\mathrm{IC}_{50}$ of Fraction A in RAW 264.7 macrophage cells were 434.8 \pm 0.75 $\mu \mathrm{g} / \mathrm{mL}$. The assay showed that Fraction A was not toxic towards RAW 264.7 cells growth. 


\section{CONCLUSION}

The nature of compounds presents in J. curcas root methanolic extract which possessed antiinflammatory without cytoxicity activity in RAW 264.7 macrophage cells in vitro was elucidated. The compounds were identified as long chain fatty acids with 18 carbons based on mass spectrophotometry and NMR analysis. The $\mathrm{IC}_{50}$ value of Fraction $\mathrm{A}$ in $\mathrm{NO}$ inhibition was $434.8 \pm 0.75 \mu \mathrm{g} / \mathrm{mL}$.

\section{ACKNOWLEDGEMENTS}

The authors would like to acknowledge Universiti Putra Malaysia for providing the facilities. This research was funded by the research grant provided by the Ministry of Education, Malaysia under the Fundamental Research Grant Scheme (FRGS) (No: 01-01-12-1095 FR).

\section{REFERENCES}

Adolf, W., Opferkuch, H. J., \& E. Hecker. 1984. Irritant phorbol derivatives from four Jatropha species. Phytochemistry 23 (1): 129-32.

Aparna, V., Kalarickal V. D., Pradeep K. M., Ponnuraj K., Chittalakkottu S., \& Madathilkovilakathu H. 2012. Antiinflammatory property of $\mathrm{n}$-hexadecanoic acid: structural evidence and kinetic assessment. Chemical Biology \& Drug Design 80 (3): 434-39.

Asase, A., Alfred A. Oteng-Yeboah, George T. O., \& Monique S. J. S. 2005. Ethnobotanical study of some Ghanaian antimalarial plants. Journal of Ethnopharmacology 99 (2): 273-79.

Ballou, L. R. \& Cheung W. Y. 1985. Inhibition of human platelet phospholipase A2 activity by unsaturated fatty acids. Proceedings of the National Academy of Sciences of the United States of America 82 (2): 371-75.

Berg, A. J. van den, Horsten, S. F., Kettenes-van den Bosch, J. J., Kroes, B.H., Beukelman, C. J., Leeflang, B. R., \& Labadie R. P. 1995. Curcacycline A--a novel cyclic octapeptide isolated from the latex of Jatropha curcas L." FEBS Letters 358 (3): 215-218.

Calder, P. C. 2004. N-3 fatty acids and cardiovascular disease: evidence explained and mechanisms explored. Clinical Science 107 (1): 1-11.

Comerford, S. C. 1996. Medicinal plants of two Mayan healers from San Andres, Peten, Guatemala. Economic Botany 50 (3): 327-36.

Diaz, B. L. \& Jonathan P. A. 2003. Phospholipase A2. Prostaglandins Leukotrienes and Essential Fatty Acids 69 (2-3): 87-97.

Goonasekera, M. M, Gunawardana, V. K., Jayasena, K., Mohammed, S. G., \& Balasubramaniam, S. 1995. Pregnancy terminating effect of Jatropha curcas in rats. Journal of Ethnopharmacology 47 (3): 117-23.

Hendra, R., Syahida, A., Ehsan, O., Aspollah, S., \& Shukor, M. Y. 2011. Antioxidant, anti-inflammatory and cytotoxicity of Phaleria macrocarpa (Boerl.) Scheff fruit. BMC Complementary and Alternative Medicine 11 (1): 110.

Kazłowska, K., Todd, H., Chia-Chung, H., Wen-Chin, Y., \& GuoJane T. 2010. Anti-inflammatory properties of phenolic compounds and crude extract from Porphyra dentata. Journal of Ethnopharmacology 128 (1): 123-30..

Kudo, I. \& Makoto, M. 2002. Phospholipase A2 enzymes. Prostaglandins \& Other Lipid Mediators 68-69: 3-58.

Kumar, A. \& Satyawati, S. 2008. An evaluation of multipurpose oil seed crop for industrial uses (Jatropha curcas L.): a review. Industrial Crops and Products 28 (1): 1-10.

Lee, H.S., Dinesh B., Gyeong-Seon L., Deok-Seon R., HyunKyung K., Dong-Hee S., \& Dong-Seok L. 2013. Antiinflammatory effect of the hexane fraction from Orostachys japonicus in RAW 264.7 cells by suppression of NF-KB and PI3K-Akt signaling. Journal of Functional Foods 5 (3): 121725.

Makkar, H. P., Becker, K., \& Schmook, B. 1998. Edible provenances of Jatropha curcas from Quintana Roo State of Mexico and effect of roasting on antinutrient and toxic factors in seeds. Plant Foods for Human Nutrition (Dordrecht, Netherlands) 52 (1): 31-36.

Mathavi, P., Nethaji, S., \& Velavan. 2013. GC-MS analysis of phytocomponents in the methanolic extract of Shorea robusta. International Journal of Science and Research (IJSR) ISSN (Online Index Copernicus Value Impact Factor 14 (6): 2319_ 7064.

Méndez, L., Janne R., César I., Billmary C., \& Rubén G. 2014. "Jatropha curcas leaves analysis, reveals it as mineral source for low sodium diets. Food Chemistry 165 (December): 575 77.

Mujumdar, A M \& Misar, A .V. 2004. Anti-inflammatory activity of Jatropha curcas roots in mice and rats. Journal of Ethnopharmacology 90 (1): 11-15.

Nayak, B. S. \& Patel, K. N. 2010. Anti-inflammatory screening of Jatropha curcas root, stem and leaf in albino rats. Romanian Journal of Biology-Plant Biology 55: 9-13.

Oskoueian, E., Norhani, A., Wan, Z. S., Abdul, R. O., Syahida, A., Wen, B. K., Nor, A. Z., Rudi, H., \& Yin, W. H. 2011. Journal of Medicinal Plant Research. Journal of Medicinal Plants Research. Vol. 5. Academic Journals.

Othman, A. R., Norhani, A., Syahida, A., Intan, S. I., \& Mohamad, P. Z. 2015. Elucidation of in-vitro anti-inflammatory bioactive compounds isolated from Jatropha curcas L. plant root. BMC Complementary and Alternative Medicine 15 (1): 11.

Pandey, V. C., Kripal, S., Jay, S. S., Akhilesh, K., Bajrang, S., \& Rana, P. S. 2012. Jatropha curcas: a potential biofuel plant for sustainable environmental development. Renewable and Sustainable Energy Reviews 16 (5): 2870-83.

Sabandar, C. W., Norizan, A., Faridahanim, M. J., \& Sahidin, I. 2013. Medicinal property, phytochemistry and pharmacology of several Jatropha species (Euphorbiaceae): a review. Phytochemistry 85: 7-29.

Santos, A. F. dos, and Antônio, E. G. S. A. 1999. Molluscicidal activity of the diterpenoids jatrophone and jatropholones A and B isolated Fromjatropha elliptica (Pohl) Muell. Arg. Phytotherapy Research 13 (8): 660-64.

Syahida, A., Israf, D. A., Lajis, N. H., Khozirah, S., Habsah, M., Permana, D., Norhadiani, I., \& Norhadiani, I. 2006. Effect of compounds isolated from natural products on IFN- $\gamma$ /LPS-Induced nitric oxide production in RAW 264.7 macrophages. Pharmaceutical Biology 44 (1): 50-59. 